\title{
Fifteen minutes of left prefrontal repetitive transcranial magnetic stimulation acutely increases thermal pain thresholds in healthy adults
}

\author{
Jeffrey J Borckardt $\mathrm{PhD}^{1}$, Arthur R Smith $\mathrm{MD}^{2}$, Scott T Reeves $\mathrm{MD}^{2}$, Mitchell Weinstein $\mathrm{MD}^{2}$, \\ F Andrew Kozel MD MSCR ${ }^{3}$, Ziad Nahas MD ${ }^{1}$, Neal Shelley BS ${ }^{2}$, R Kyle Branham BS ${ }^{4}$, \\ $\mathrm{K}$ Jackson Thomas PT EdD ${ }^{5}$, Mark S George $\mathrm{MD}^{6}$
}

JJ Borckardt, AR Smith, ST Reeves, et al. Fifteen minutes of left prefrontal repetitive transcranial magnetic stimulation acutely increases thermal pain thresholds in healthy adults. Pain Res Manage 2007;12(4):287-290.

BACKGROUND: Transcranial magnetic stimulation (TMS) of the motor cortex appears to alter pain perception in healthy adults and in patients with chronic neuropathic pain. There is, however, emerging brain imaging evidence that the left prefrontal cortex is involved in pain inhibition in humans.

OBJECTIVE: Because the prefrontal cortex may be involved in descending pain inhibitory systems, the present pilot study was conducted to investigate whether stimulation of the left prefrontal cortex via TMS might affect pain perception in healthy adults.

METHODS: Twenty healthy adults with no history of depression or chronic pain conditions volunteered to participate in a pilot laboratory study in which thermal pain thresholds were assessed before and after 15 min of repetitive TMS (rTMS) over the left prefrontal cortex $(10 \mathrm{~Hz}, 100 \%$ resting motor threshold, $2 \mathrm{~s}$ on, $60 \mathrm{~s}$ off, 300 pulses total). Subjects were randomly assigned to receive either real or sham rTMS and were blind to condition.

RESULTS: Subjects who received real rTMS demonstrated a significant increase in thermal pain thresholds following TMS. Subjects receiving sham TMS experienced no change in pain threshold.

CONCLUSIONS: rTMS over the left prefrontal cortex increases thermal pain thresholds in healthy adults. Results from the present study support the idea that the left prefrontal cortex may be a promising TMS cortical target for the management of pain. More research is needed to establish the reliability of these findings, maximize the effect, determine the length of effect and elucidate possible mechanisms of action.

Key Words: Left prefrontal cortex; Pain; Thermal pain thresholds; TMS

$\mathrm{T}$ ranscranial magnetic stimulation (TMS) is a relatively noninvasive brain stimulation technology that can focally stimulate the brain of an awake individual $(1,2)$. A localized pulsed magnetic field transmitted through a figure-eight coil induces electrical currents in the brain (3) and focally stimulates the cortex by depolarizing superficial neurons $(4,5)$. TMS at different intensities, frequencies and coil angles can excite several elements (eg, cell bodies, axons) of various neuronal
Quinze minutes de stimulation magnétique crânienne préfrontale gauche répétitive accroît considérablement les seuils de douleur thermique chez des adultes en santé HISTORIQUE : La stimulation magnétique crânienne (SMC) du cortex
moteur semble modifier la perception de la douleur chez des adultes en
santé et des patients souffrant d'une douleur névropathique chronique.
Cependant, d'après des données probantes en imagerie cérébrale, le cor-
tex préfrontal gauche contribue à l'inhibition de la douleur chez les
humains.

OBJECTIF : Puisque le cortex préfrontal peut participer aux systèmes d'inhibition de la douleur descendante, la présente étude pilote visait à explorer si la stimulation du cortex préfrontal gauche par SMC modifiait la perception de la douleur chez des adultes en santé.

MÉTHODOLOGIE : Vingt adultes en santé sans antécédents de dépression ou de troubles de douleur chronique se sont portés volontaires pour participer à un projet pilote de laboratoire au cours duquel on évaluait leurs seuils de douleur thermique avant et après une SMC répétitive (SMCr) de 15 minutes sur le cortex préfrontal gauche $(10 \mathrm{~Hz}$, seuil moteur au repos $100 \%, 2 \mathrm{~s}$ en fonction, $60 \mathrm{~s}$ hors fonction, total de 300 pulsations). Les sujets étaient distribués au hasard entre une $\mathrm{SMCr}$ réelle ou simulée et n'étaient pas au courant du conditionnement.

RÉSULTATS : Les sujets qui ont reçu une SMCr réelle ont démontré une importante augmentation de leur seuil de douleur thermique après la SMC. Les sujets qui ont reçu la SMCr simulée n'ont démontré aucun changement.

CONCLUSIONS : Une SMCr appliquée sur le cortex préfrontal gauche accroît les seuils de douleur chez des adultes en santé. Les résultats de la présente étude étayent l'idée selon laquelle le cortex préfrontal gauche serait une cible corticale prometteuse de SMC pour le traitement de la douleur. D'autres recherches s'imposent pour déterminer la fiabilité de ces observations, en maximiser l'effet, en établir la durée et élucider les mécanismes d'action éventuels.

groups (eg, interneurons, neurons projecting into other cortical areas) (6-8). When TMS pulses are delivered repeatedly, it is referred to as repetitive TMS (rTMS).

Several studies have found that rTMS delivered over the motor cortex can affect the perception of laboratory-induced pain in healthy adults as well as chronic neuropathic pain in clinical samples (9-17). While the effects observed in most of these studies appears to be short-lived, a recent study (18)

\footnotetext{
${ }^{1}$ Department of Psychiatry and Behavioral Sciences; ${ }^{2}$ Department of Anesthesiology and Perioperative Medicine, Medical University of South Carolina; ${ }^{3}$ Department of Psychiatry, UT Southwestern Medical Center; ${ }^{4}$ College of Medicine; ${ }^{5}$ College of Health Professions; ${ }^{6}$ Departments of Psychiatry, Neuroscience and Radiology, Medical University of South Carolina, Charleston, South Carolina, USA

Correspondence: Dr Jeffrey J Borckardt, Department of Psychiatry and Behavioral Sciences, Medical University of South Carolina, 171 Ashley

Avenue, Charleston, South Carolina 29425, USA. Telephone 843-792-3295, fax 843-792-5702, e-mail borckard@musc.edu
} 
demonstrated that the antinociceptive effects are sustained for at least 15 days following three consecutive days of motor cortex rTMS (18).

The motor cortex has been a popular target for pain management. However, findings from numerous rTMS depression treatment trials and from studies integrating TMS and functional magnetic resonance imaging suggest that TMS over the prefrontal cortex can cause secondary changes in pain and mood regulating regions. These regions include the cingulate gyrus, orbitofrontal cortex, insula, and hippocampus (19). There is evidence to support the idea that left prefrontal activation is negatively correlated with pain experience (20), suggesting the prefrontal cortex governs pain perception. Additionally, diffusion tensor imaging technology has been used to uncover anatomical circuitry connecting the prefrontal cortex with both the nucleus cuneiformis and periaquaductal grey. This supports the potential role of the prefrontal cortex in the functionally characterized top-down pain inhibitory system (21). To date, a few studies have demonstrated analgesic effects with prefrontal cortex TMS $(22-25)$.

No published studies to date have investigated the effects of fast rTMS over the left prefrontal cortex on pain perception using a controlled laboratory paradigm. Given emerging evidence of the role of the left prefrontal cortex in pain inhibition, stimulation of the prefrontal cortex using fast rTMS may produce analgesic effects. The present preliminary pilot trial sought to test whether $15 \mathrm{~min}$ of fast left prefrontal rTMS could change pain thresholds in a small cohort of healthy adults.

\section{METHODS}

The present study was approved by the Institutional Review Board in the Office of Research Integrity at the Medical University of South Carolina, USA. Twenty subjects (11 men) without history of depression or chronic pain disorders (assessed during clinical interview) volunteered to participate in this study (mean age 31.65 years). After written informed consent was obtained from the study participants, a TSA-II NeuroSensory Analyzer (Medoc Ltd, Israel) with a $30 \mathrm{~mm} \times$ $30 \mathrm{~mm}$ thermode stimulating area was used to determine thermal pain thresholds using the method of limits. The thermode was attached to each subject's left volar forearm $5 \mathrm{~cm}$ from the wrist. The thermode was programmed to start heating from the adaptation temperature of $32^{\circ} \mathrm{C}$ at a rate of $1^{\circ} \mathrm{C} / \mathrm{s}$. Subjects were instructed to press a button when the sensation reached the level they considered painful. The temperature of the thermode at the time of the button press was recorded and the thermode rapidly cooled to $32^{\circ} \mathrm{C}$. Subjects rested for $30 \mathrm{~s}$ between each trial. The first of the five trials was discarded, and the mean of the subsequent four trials was used to represent baseline thermal pain threshold.

Next, subjects underwent a standard resting motor threshold assessment using a Neuronetics Neopulse TMS machine (Neuronetics, USA) with a figure-eight coil. The TMS machine was initially set to $40 \%$ of its maximal output at $0.5 \mathrm{~Hz}$. The TMS administrator located the area of the scalp that produced visible thumb movement upon TMS stimulation by systematically moving the coil around the scalp while adjusting the intensity. Next, adaptive parameter estimation by sequential testing (PEST) procedures were conducted with the aid of custom-developed software to determine the amount of machine output necessary to produce visible thumb movement
$50 \%$ of the time. This value was termed the resting motor threshold (rMT) (26-28).

Subjects were then randomly assigned to receive $15 \mathrm{~min}$ of active $(n=10)$ or sham $(n=10)$ left prefrontal rTMS $(10 \mathrm{~Hz}$, $100 \%$ rMT, 2 s on, 60 s off, total of 300 pulses). The left prefrontal location was determined according to convention by measuring $5 \mathrm{~cm}$ anterior in a parasagittal line from the optimum scalp location for producing right thumb movement (29. 31). Sham rTMS was conducted with a specially designed sham coil that looked and sounded similar to the active coil but had a hidden aluminum plate blocking actual stimulation.

Immediately following the 15 min of prefrontal rTMS, thermal pain thresholds were assessed again in the manner described above.

Mean thermal pain thresholds were evaluated between groups (sham versus real rTMS) using a mixed ANOVA model with time (pre- to post-TMS) as a within-subject factor. Subjects' individual intercepts were entered into the model as subject-level random effects to control for individual differences in baseline thermal pain thresholds.

\section{RESULTS}

The mean $( \pm$ SEM) pre-TMS thermal threshold of subjects in the real TMS group was $45.81 \pm 0.58^{\circ} \mathrm{C}$. The mean threshold post-TMS increased to $46.50 \pm 0.43^{\circ} \mathrm{C}$. The mean pre-TMS thermal threshold of subjects in the sham TMS group was $47.17 \pm 0.40^{\circ} \mathrm{C}$. The post-TMS mean threshold was $46.93 \pm 0.41^{\circ} \mathrm{C}$

There was no overall difference between groups with respect to mean thermal pain threshold $(F[1,18]=2.23$, P not significant) but there was a significant difference in pain thresholds before and after TMS $(F[1,18]=6.25, \mathrm{P}=0.02)$. Post hoc analyses (least square difference with Tukey-Kramer adjustment) indicate that mean thermal pain thresholds were significantly higher after $\mathrm{rTMS}(\mathrm{t}[18]=2.50, \mathrm{P}=0.02)$. A significant group (real versus sham TMS) by time (pre- to postTMS) interaction $(\mathrm{F}[1,18]=23.67, \mathrm{P}<0.0001)$ indicated subjects who received active rTMS demonstrated a significant increase in thermal pain threshold $(\mathrm{t}[18]=5.20, \mathrm{P}=0.0003)$ whereas subjects in the sham group did not $(\mathrm{t}[18]=1.68$, P not significant).

No serious negative consequences of left prefrontal rTMS were observed. One subject from each group (active and sham) reported a mild headache following rTMS. Neither of the reported headaches were severe nor did subjects report using any pain medications to manage the headaches. Headache is a common risk of rTMS and is presented to subjects during the informed consent process.

\section{DISCUSSION}

The present study used a simple laboratory thermal pain paradigm to show that stimulation of the left prefrontal cortex for $15 \mathrm{~min}$ is associated with an increase in thermal pain threshold in healthy adults. A significant increase in pain threshold was detected pre-to post-TMS in subjects who received real TMS, but not among participants who received sham TMS.

Most of the published TMS and pain studies targeted the motor cortex. While this cortical target appears to be a reasonable one given the observed analgesic effects of motor cortex stimulation (via TMS and via implanted electrodes), little is known about the effects of stimulating other cortical areas. Given that pain is a complex experience with sensory, affective 
and cognitive components, it seems reasonable to continue to investigate different cortical targets that may be involved in different aspects of pain experience. There is emerging evidence from brain imaging studies suggesting that TMS over the left prefrontal cortex results in modulation of deeper limbic structures likely involved in the affective dimension of pain experience such as the cingulate gyrus, orbitofrontal cortex, insula and hippocampus (19). Additionally, Lorenz et al (20) found that left prefrontal cortical activation is negatively correlated with pain experience suggesting a governing role of the prefrontal cortex on pain perception. Activation of the left prefrontal cortex (via TMS or other methods such as cognitive therapy) may activate descending pain inhibitory networks through the nucleus cuneiformis and periaquaductal grey (21).

While the present study raises interesting questions about rTMS effects on pain perception, it does not provide definitive answers. One limitation has to do with the nature of the sham condition. There is some emerging evidence that rTMS can be painful for some patients, whereas sham rTMS is usually not painful. It is possible that, for some subjects, pain associated with active rTMS may have resulted in activation of antinociceptive processes, including endogenous opioid release. Unfortunately, this potential limitation plagues the majority of rTMS and pain research to date. Future studies of rTMS effects on pain perception should employ more sophisticated sham conditions that are matched to real rTMS with respect to painfulness, or at the very least, painfulness ratings of the rTMS should be collected to permit statistical control for the painfulness of rTMS.

Another limitation of the present study is that this preliminary trial is small $(n=20)$, and only thermal pain thresholds were examined. The purpose of this investigation was to determine if any detectable analgesic effects of prefrontal stimulation were present in healthy adults to allow for planning of more systematic and comprehensive TMS studies in the future. Thermal threshold assessment with a Peltier thermode via the method of limits is a simple, widely accepted, sensitive and accurate laboratory measure of pain perception in healthy adult samples. Given the very preliminary scope of this pilot study, the focus was limited to determine if any effects were present that warranted future investigation.

\section{REFERENCES}

1. George MS, Nahas Z, Kozel FA, et al. Mechanisms and the current state of transcranial magnetic stimulation. CNS Spectr 2003;8:496-514.

2. Barker AT, Jalinous R, Freeston IL. Non-invasive magnetic stimulation of the human motor cortex. Lancet 1985;1:1106-7.

3. Barker AT, Freeston IL, Jarratt JA, Jalinous R. Magnetic stimulation of the human nervous system: An introduction and basic principles. In: Chokroverty S, ed. Magnetic Stimulation in Clinical Neurophysiology, 1st edn. Boston: Butterworths, 1990:55-72.

4. George MS, Belmaker RH, eds. Transcranial Magnetic Stimulation in Neuropsychiatry, 1st edn. Washington: American Psychiatric Press, 2000.

5. George MS, Lisanby SH, Sackeim HA. Transcranial magnetic stimulation: Applications in neuropsychiatry. Arch Gen Psychiatry 1999;56:300-11.

6. Roth BJ, Saypol JM, Hallett M, Cohen LG. A theoretical calculation of the electric field induced in the cortex during magnetic stimulation. Electroencephalogr Clin Neurophysiol 1991;81:47-56.

7. Amassian VE, Eberle L, Maccabee PJ, Cracco RQ. Modelling magnetic coil excitation of human cerebral cortex with a peripheral nerve immersed in a brain-shaped volume conductor: The
The mean of the baseline thermal threshold for the sham group was higher than the mean for participants in the real TMS at baseline, possibly due to the small population. The small population, the use of thermal pain thresholds and the laboratory setting need to be considered when attempting to generalize the effects of prefrontal rTMS on clinical pain.

The duration of analgesic effects of prefrontal rTMS is unknown and future studies should consider evaluating the temporal course of this effect in both clinical and laboratory settings. Much of the TMS depression research to date seems to suggest that daily rTMS over several weeks can lead to longterm functional and possibly structural reorganization of cortical and subcortical neural connections. Along these lines, the ethics of TMS research on healthy adults has recently been called into question (32). However, the evidence available suggests that the effects of a single session of TMS on pain perception are short-lived (less than $45 \mathrm{~min}$ ). To produce detectable, lasting changes, it appears that TMS needs to be delivered daily over several weeks. It is theoretically possible that undesirable, undetectable biological changes could occur in response to low doses (300 pulses) and single sessions of TMS. However, despite extensive use of TMS on humans and nonhuman animals since modern TMS was developed in 1985, no such problems have been found (33-37). It is also possible for TMS to cause detectable temporary problems such as headaches and seizures. In the present study, all participants were informed of the potential for these risks, as well as the fact that TMS is an intervention under investigation and there may be presently unknown long-term negative effects. The people who volunteered for the present study participated with full knowledge of these risks. It is believed that TMS may help chronic pain sufferers in the future and the risks associated with developing this therapeutic area are offset by the potential benefits.

Although the current study does not directly compare the effects of prefrontal stimulation with the effects of motor cortex stimulation, it does provide some preliminary evidence suggesting that future studies on the effects of prefrontal stimulation are warranted. Future studies of prefrontal TMS for pain should implement measures designed to separate the sensory, affective and cognitive components of pain perception.

significance of fiber bending in excitation. Electroencephalogr Clin Neurophysiol 1992;85:291-301.

8. Davey KR, Cheng CH, Epstein CM. Prediction of magnetically induced electric fields in biological tissue. IEEE Trans Biomed Eng 1991;38:418-22.

9. Migita K, Uozumi T, Arita K, Monden S. Transcranial magnetic coil stimulation of motor cortex in patients with central pain. Neurosurgery 1995;36:1037-9.

10. Rollnik JD, Wüstefeld S, Däuper J, et al. Repetitive transcranial magnetic stimulation for the treatment of chronic pain - a pilot study. Eur Neurol 2002;48:6-10.

11. Lefaucheur JP, Drouot X, Keravel Y, Nguyen JP. Pain relief induced by repetitive transcranial magnetic stimulation of precentral cortex. Neuroreport 2001;12:2963-5.

12. Töpper R, Foltys H, Meister IG, Sparing R, Boroojerdi B. Repetitive transcranial magnetic stimulation of the parietal cortex transiently ameliorates phantom limb pain-like syndrome. Clin Neurophysiol 2003;114:1521-30.

13. Pleger B, Janssen F, Schwenkreis P, Völker B, Maier C, Tegenthoff M. Repetitive transcranial magnetic stimulation of the motor cortex attenuates pain perception in complex regional pain syndrome type I. Neurosci Lett 2004;356:87-90.

14. Tamura Y, Okabe S, Ohnishi T, et al. Effects of $1-\mathrm{Hz}$ repetitive 


\section{Borckardt et al}

transcranial magnetic stimulation on acute pain induced by capsaicin. Pain 2004;107:107-15.

15. Summers J, Johnson S, Pridmore S, Oberoi G. Changes to cold detection and pain thresholds following low and high frequency transcranial magnetic stimulation of the motor cortex. Neurosci Lett 2004;368:197-200.

16. Lefaucheur JP, Drouot X, Ménard-Lefaucheur I, Nguyen JP. Neuropathic pain controlled for more than a year by monthly sessions of repetitive transcranial magnetic stimulation of the motor cortex. Neurophys Clin 2004;34:91-5.

17. Canavero S, Bonicalzi V, Dotta M, Vighetti S, Asteggiano G, Cocito D. Transcranial magnetic cortical stimulation relieves central pain. Stereotact Funct Neurosurg 2002;78:192-6.

18. Khedr EM, Kotb H, Kamel NF, Ahmed MA, Sadek R, Rothwell JC. Longlasting antalgic effects of daily sessions of repetitive transcranial magnetic stimulation in central and peripheral neuropathic pain. J Neurol Neurosurg Psychiatry 2005;76:833-8

19. George MS, Wassermann EM. Rapid-rate transcranial magnetic stimulation and ECT. Convuls Ther 1994;10:251-4.

20. Lorenz J, Minoshima S, Casey KL. Keeping pain out of mind: The role of the dorsolateral prefrontal cortex in pain modulation. Brain 2003;126;1079-91.

21. Hadjipavlou G, Dunckley P, Behrens TE, Tracey I. Determining anatomical connectivities between cortical and brainstem pain processing regions in humans: A diffusion tensor imaging study in healthy controls. Pain 2006;123:169-78.

22. Reid P, Pridmore S. Improvement in chronic pain with transcranial magnetic stimulation. Aust N Z J Psychiatry 2001;35:252.

23. Graff-Guerrero A, González-Olvera J, Fresán A, Gómez-Martín D, Méndez-Núñez JC, Pellicer F. Repetitive transcranial magnetic stimulation of dorsolateral prefrontal cortex increases tolerance to human experimental pain. Brain Res Cogn Brain Res 2005;21:153-60.

24. Borckardt JJ, Weinstein M, Reeves ST, et al. Postoperative left prefrontal repetitive transcranial magnetic stimulation reduces patient-controlled analgesia use. Anesthesiology 2006;105:557-62.

25. Avery DH, Holtzheimer PE III, Fawaz W, et al. Transcranial magnetic stimulation reduces pain in patients with major depression: A sham-controlled study. J Nerv Ment Dis 2007;195:378-81.

26. Pentland A. Maximum likelihood estimation: The best PEST. Percept Psychophys 1980;28:377-9.
27. Mishory A, Molnar C, Koola J, et al. The maximum-likelihood strategy for determining transcranial magnetic stimulation motor threshold, using parameter estimation by sequential testing is faster than conventional methods with similar precision. J ECT 2004;20:160-5

28. Borckardt JJ, Nahas Z, Koola J, George MS. Estimating resting motor thresholds in transcranial magnetic stimulation research and practice: A computer simulation evaluation of best methods. J ECT 2006;22:169-75.

29. George MS, Wassermann EM, Kimbrell TA, et al. Mood improvement following daily left prefrontal repetitive transcranial magnetic stimulation in patients with depression: A placebocontrolled crossover trial. Am J Psychiatry 1997;154:1752-6.

30. George MS, Wassermann EM, Williams WA, et al. Changes in mood and hormone levels after rapid-rate transcranial magnetic stimulation (rTMS) of the prefrontal cortex. J Neuropsychiatry Clin Neurosci 1996;8:172-80.

31. George MS, Wassermann EM, Williams WA, et al. Daily repetitive transcranial magnetic stimulation (rTMS) improves mood in depression. Neuroreport 1995;6:1853-6.

32. Jones LS. The ethics of transcranial magnetic stimulation. Science 2007;315:1663-4.

33. O'Reardon JP, Solvason HB, Janicak PG, et al. Efficacy and safety of transcranial magnetic stimulation in the acute treatment of major depression: A multi-site randomized controlled trial. Biol Psychiatry 2007. In press.

34. Anderson B, Mishory A, Nahas Z, et al. Tolerability and safety of high daily doses of repetitive transcranial magnetic stimulation in healthy young men. J ECT 2006;22:49-53.

35. Nahas Z, Li X, Kozel FA, et al. Safety and benefits of distanceadjusted prefrontal transcranial magnetic stimulation in depressed patients 55-75 years of age: A pilot study. Depress Anxiety 2004; 19:249-56.

36. Li X, Nahas Z, Lomarev M, et al. Prefrontal cortex transcranial magnetic stimulation does not change local diffusion: A magnetic resonance imaging study in patients with depression. Cogn Behav Neurol 2003;16:128-35.

37. Nahas Z, DeBrux C, Chandler V, et al. Lack of significant changes on magnetic resonance scans before and after 2 weeks of daily left prefrontal repetitive transcranial magnetic stimulation for depression. J ECT 2000;16:380-90. 


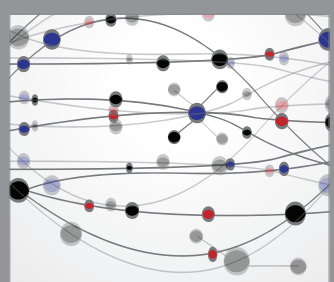

The Scientific World Journal
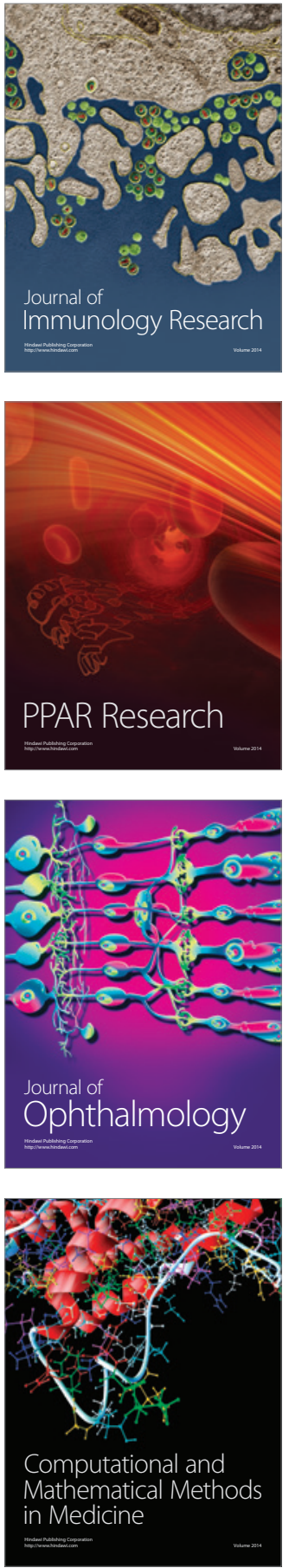

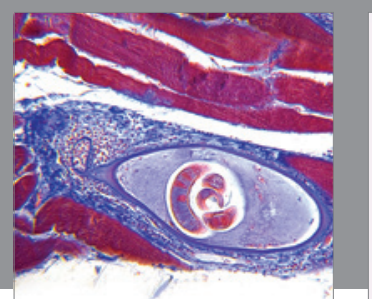

Gastroenterology Research and Practice

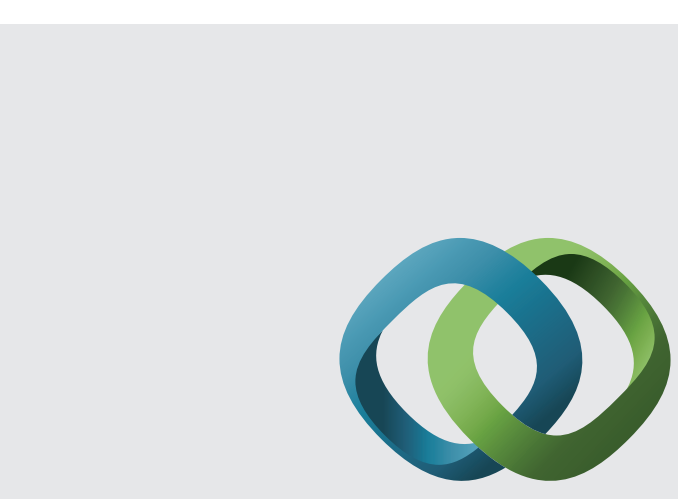

\section{Hindawi}

Submit your manuscripts at

http://www.hindawi.com
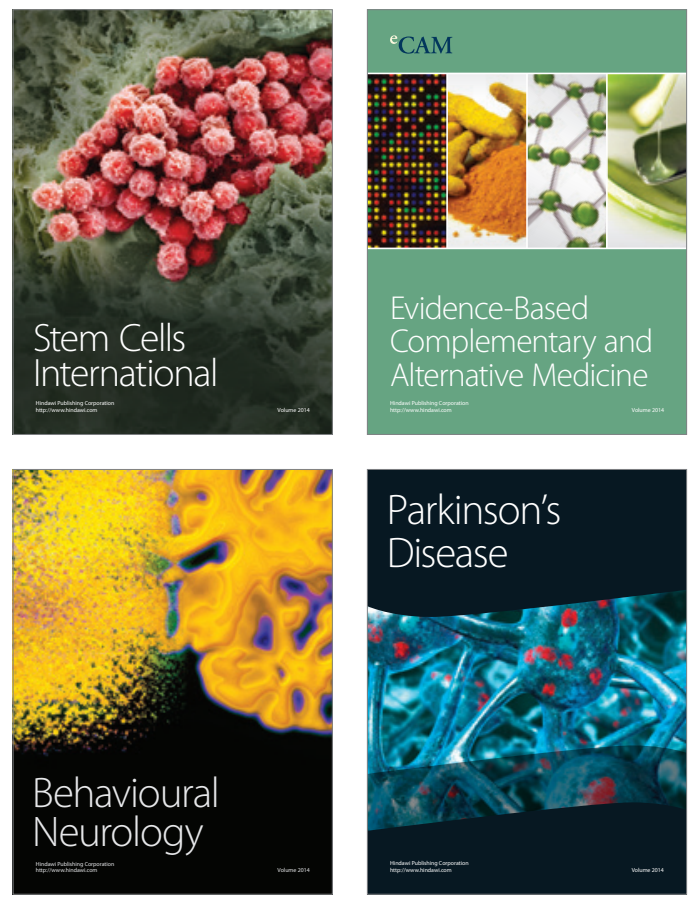
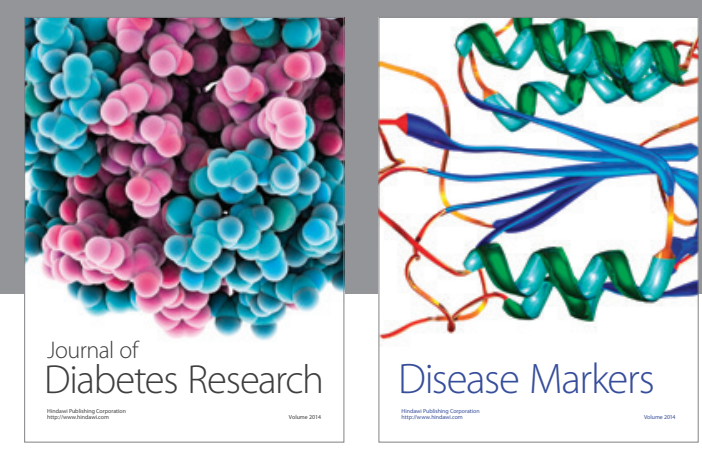

Disease Markers
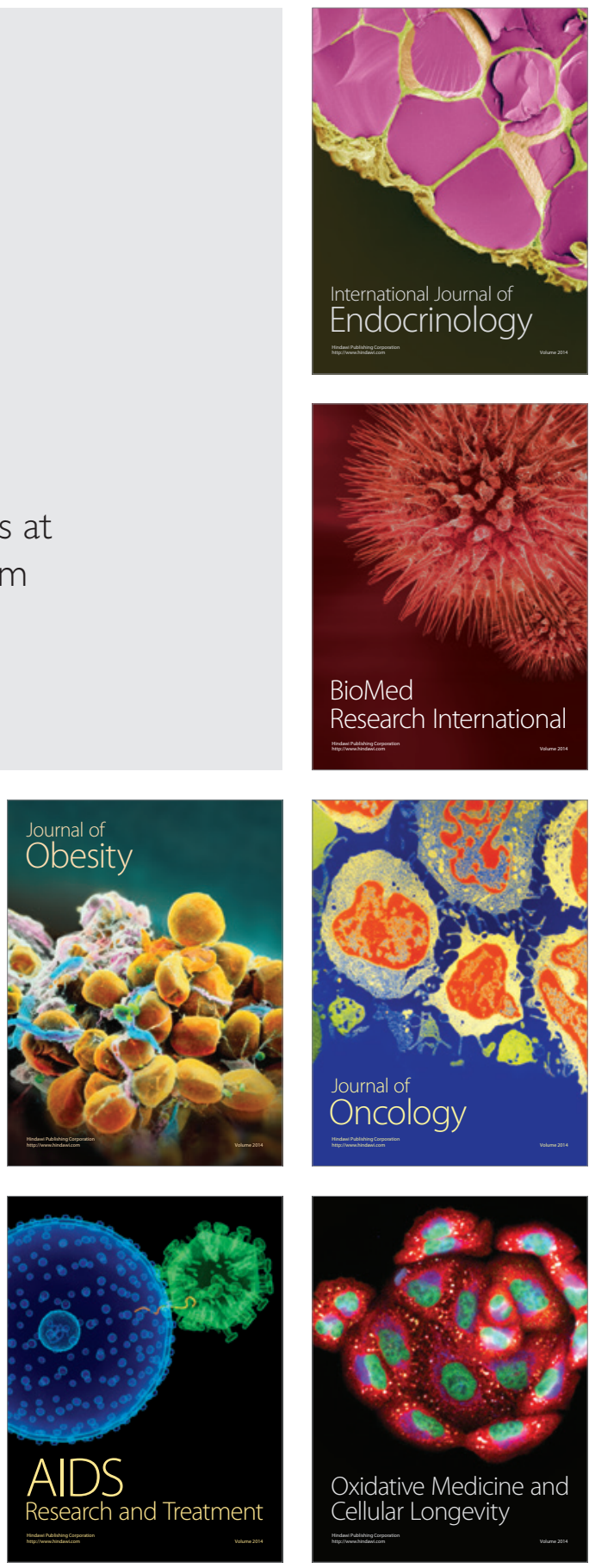